\title{
Source Footprint Considerations in the Determination of Volatile Organic Compound Fluxes from Forest Canopies
}

\author{
S. K. Kaharabata AND P. H. SchuepP \\ Department of Natural Resource Sciences, McGill University, Ste-Anne-de-Bellevue, Quebec, and \\ Centre for Climate and Global Change Research, McGill University, Montreal, Quebec, Canada \\ J. D. Fuentes \\ Department of Environmental Sciences, University of Virginia, Charlottesville, Virginia
}

(Manuscript received 2 December 1997, in final form 18 August 1998)

\begin{abstract}
Above-canopy sampling of trace gases to determine volatile organic compound (VOC) emissions should be interpreted in terms of footprint considerations. This can be accomplished by defining the upwind canopy areas effectively sampled under the given wind and stability conditions. Using solutions of the advection-diffusion equation adjusted through controlled tracer gas $\left(\mathrm{SF}_{6}\right)$ release experiments in the Boreal Ecosystem Atmosphere Study of 1994, sampling of VOC concentrations and fluxes over a forest whose VOC sources are heterogeneous (Camp Borden) are studied. Analysis demonstrates that the variability observed in measured VOC fluxes could be accounted for by varying numbers of randomly distributed clumps of emitter species within a varying footprint. It suggests that heterogeneity of the forest canopy, in terms of source distribution of VOCs, has to be explicitly considered in estimates of source strength from above-canopy concentration/flux sampling.
\end{abstract}

\section{Introduction}

Volatile organic compounds (VOCs) are emitted into the atmosphere by certain forest tree species. Isoprene, one of the most abundantly emitted VOCs, both globally (Guenther et al. 1995) and from North American forests (Guenther et al. 1994), reacts quickly with various chemical species, resulting in the formation of carbon monoxide, free radicals, and strong oxidants that can contribute to climate change (Fehsenfeld et al. 1992). In order to confidently estimate VOC fluxes from abovecanopy measurements and physiological/microclimatological emission models, it is necessary to determine the upwind source distribution of emitting trees within the footprint (FP), that is, the upwind canopy area effectively sampled by the above-canopy concentration or flux measurement. The prediction of the FP requires a high-resolution vegetation survey (Fuentes et al. 1999) and detailed meteorological observations. Uncertainty about the FP dimensions, and about the distribution of emitter species within it, has been identified as one of the factors that may cause these emission models to overestimate measurements by as much as $200 \%$ for a heterogeneous forest (Fuentes et al. 1996; Lamb et al.

Corresponding author address: Dr. Samuel Kaharabata, 217, 15 Sherwood Ave., Toronto, ON, M4P 2A6 Canada.]

E-mail: SKaharabata@mail.globalserve.net
1996). Fuentes et al. (1999) showed that for a homogeneous stand of trembling aspen (Populus tremuloides) model predictions agreed well with flux estimates based on above-canopy concentration gradients and cuvetteenclosed leaf-branch isoprene emissions.

The FP is directly related to measurement height and atmospheric stability. Recently, a number of studies have attempted to quantify the FP over different surface vegetation cover and atmospheric stabilities using either analytical solutions to the diffusion-advection equation or Lagrangian simulation of particle/fluid trajectories within the surface layer (Leclerc and Thurtell 1990; Schuepp et al. 1990; Schuepp et al. 1992; Wilson and Swaters 1991; Horst and Weil 1992, 1994; Schmid 1994; Finn et al. 1996; Kaharabata et al. 1997). In this paper, we examine the effects of FP size and source distribution within the FP on the interpretation of measured isoprene emissions from a mixed deciduous forest. Tower data from the Camp Borden site in Ontario will be used (Lo 1995; Fuentes et al. 1996).

\section{Footprint model}

In an Eulerian reference frame, the concentration $C$ of a diffusing scalar measured at height $z_{m}$ can be related to the infinite set of all upwind surface point sources of strength $Q$ at release height $z_{s}$ by

$$
C\left(0,0, z_{m}\right)=\int_{-\infty}^{\infty} \int_{0}^{\infty} Q\left(x, y, z_{s}\right) f_{C}\left(x, y, z_{m}\right) d x d y,
$$


where different forms of $f_{C}$, the FP function for $C$, can be found in the literature (Pasquill and Smith 1983; Horst and Weil 1992, 1994; Schmid 1994). The form given by Pasquill and Smith (1983) was developed using surface similarity laws with little empirical adjustment and explicitly handles stability effects. We employ their form, defined as

$$
f_{C}\left(x, y, z_{m}\right)=\frac{e^{-y^{2} / 2 \sigma_{y}^{2}}}{\sqrt{2 \pi} \sigma_{y}} \frac{e^{-\left(z_{m} / B \sigma_{z}\right)^{s}}}{A \sigma_{z} U(x)},
$$

where $(x, y, z)$ are the Cartesian coordinates; $\sigma_{y}$ and $\sigma_{z}$ the crosswind and vertical spread of the plume from each point source, respectively; and $U(x)$ is the velocity of streamwise plume advection and is a function of the weighted mean plume height $\bar{z}$. In addition, $A$ and $B$ are $\Gamma$ functions of the stability dependent vertical shape exponent $s$ in the power-law forms of $u(z)$ and $K(z)$ profiles.

If we express the vertical scalar flux simply as the gradient diffusion of the scalar concentration, that is, $F$ $=-K \partial C / \partial z$, the flux FP, denoted by subscript $F$, can be formulated as

$$
f_{F}\left(x, y, z_{m}\right)=\frac{u^{*} k}{\phi_{c}(z / L)} \frac{s z_{m}^{s}}{\left(B \sigma_{z}\right)^{s}} \frac{e^{-y^{2} / 2 \sigma_{y}^{2}}}{\sqrt{2 \pi} \sigma_{y}} \frac{e^{-\left(z z_{m} / B \sigma_{z}\right)^{s}}}{A \sigma_{z} U(x)}
$$

(Kaharabata et al. 1997). The function $\phi_{c}(z / L)$ is the stability correction for a scalar (heat) (Businger et al. 1971), $u^{*}$ is the friction velocity, and $k=0.4$ is the von Kármán constant. The complete functional forms of the symbols defined above can be found in the literature (e.g., Kaharabata et al. 1997).

Since the normalized contributions of all upwind sources $(0<x<\infty,-\infty<y<\infty)$ toward an observation of concentration or flux made at point $\left(0,0, z_{m}\right)$ must be equal to unity, Schmid (1994) outlined a procedure to calculate the $(x, y<\infty)$ isopleths for given fractional contributions $(P<1)$ to the measurement. For computational practicality, the limits $(x=\infty, y= \pm \infty)$ were replaced with the $(x, y)$ isopleth corresponding to the value of $f_{C}$ or $f_{F}$ equivalent to $1 \%$ of the maximum, and integration to these new limits was assumed to give $P$ $=1$. Contributions from sources outside these limits were considered negligible. Subsequently, for any desired $P$ fraction, the $(x, y)$ integration limits can be found by numerical search procedure. [For a step-by-step description of the procedure, please consult Schmid (1994).] We used this procedure to determine the surface area isopleth of the FP that corresponds to a desired $P$ level, and knowing the distribution of isoprene sources within this FP, inferences can be made on the emission strength and type of source species that are ultimately responsible for the measured flux. It should be noted that a model such as the one described above, formulated for surface layer scaling, cannot necessarily be assumed to be valid within the roughness layer above the forest canopy, that is, the transition layer where momentum transfer deviates from the theoretical logarithmic profile but approaches it with increasing height over a forest. To date, there is no model that describes satisfactorily the diffusion and turbulence properties above a forest canopy. Raupach et al. (1996) used surface layer scaling with adjustments above the forest canopy and the logarithmic profile laws have been well substantiated above forests (e.g., Kaimal and Finnigan 1994) with some minor adjustment in the roughness layer. Finn et al. (1996) examined footprint models including those of Horst and Weil $(1992,1994)$, which are very similar to Eqs. (1)-(3) and concluded that they should be used with caution over tall canopies such as forests, especially since there exist little experimental data under strong instability.

To test the ability of our model to adequately reproduce the observed relationship between canopy level sources and above-canopy downwind concentrations for a variety of forest types and stability conditions, controlled tracer gas $\left(\mathrm{SF}_{6}\right)$ release experiments were carried out during the Boreal Ecosystem Atmosphere Study (BOREAS) third intensive field campaign of 1994 in Thompson, Manitoba (Kaharabata et al. 1997). For a single point source, the model reliably predicted both the concentration profiles and back-calculated source strength $(\approx 60 \%$ fell within $\pm 10 \%$ of actual values) from the observed concentration profiles, with only minor adjustments. Primarily, $s$ needed to be $1.3(A=0.935, B=1.012)$ and $1.4(A=0.996, B=1.092)$ in order for Eq. (1) [with Eq. (2)] to give the best fit to observed concentration profiles and source strengths, respectively. The best fit was based on the analysis of the mean relative difference (derived from the normalized mse) between measured and calculated quantities. All measurements were taken under unstable conditions for which the literature suggests $s=1.0$, with $s$ ranging from 1 (unstable) to 2 (stable) (Pasquill and Smith 1983). The range in $s$ had been derived for a relatively smooth surface, whereas over a forest the vertical shape would conceivably be altered to reflect the rougher surface elements. In addition, the Obukhov stability length $L$ determined through profile methods needed adjustment for certain canopy types, as opposed to no adjustment when calculated from eddy correlation measurements (Kaharabata et al. 1997). The adopted solutions were therefore considered as an adequate analytical tool for footprint prediction.

\section{Experimental site}

A flux measuring tower $(48 \mathrm{~m})$ was situated within a mixed deciduous forest at Camp Borden in southern Ontario $\left(44^{\circ} 19^{\prime} \mathrm{N}, 80^{\circ} 56^{\prime} \mathrm{W}\right)$ during the summer of 1995. The site is relatively flat with fetch of about 4 $\mathrm{km}$ from the SSE to WNW directions. A red pine plantation exists immediately to the north of the site. The forest was approximately 92 years old in 1995 with a growing season from late April to late October. Mean tree height of the forest was $22 \mathrm{~m}$. Aspen, accounting for only approximately $14 \%$ of the forest flora, was found to be the main isoprene emitter (Fuentes et al. 1996). It occurred in clumps of four to six trees with 
TABLE 1 . Borden tree survey summary during 1995. Percentages are rounded to the nearest integer. Other species not listed contributed to a total of less than $1 \%$. The undergrowth was not an isoprene emitter.

\begin{tabular}{lc}
\hline \hline \multicolumn{1}{c}{ Tree } & Percent \\
\hline Beech (Fagus grandifolia) & 1 \\
Black cherry (Prunus serotina) & 2 \\
Elm (Ulmus americana) & 3 \\
Large-tooth aspen (Populus grandidentata) & 6 \\
Trembling aspen (Populus tremuloides) & 8 \\
Paper birch (Betula papyrifera) & 3 \\
Red maple (Acer rubrum) & 41 \\
Silver maple (Acer saccharinum) & 4 \\
Red pine (Pinus resinosa) & 1 \\
White pine (Pinus strobus) & 22 \\
White ash (Fraxinus americana) & 10 \\
& 101 \\
\hline
\end{tabular}

each clump having a diameter of approximately $10 \mathrm{~m}$. These clumps were uniformly distributed throughout the forest (i.e., at the forest scale) with each clump being separated randomly from the other by average distances of approximately 50-75 m. At the local scale around the tower, distribution was nonuniform. Aspen height ranged from 18 to $22 \mathrm{~m}$, with foliage density concentrated between 15 and $20 \mathrm{~m}$. A tree survey of the site conducted in 1995 is given in Table 1.

During the growing season of 1995, ambient air samples were collected at heights of 30 and $42 \mathrm{~m}$ on the tower. The air samples were then analyzed for isoprene and other VOCs. A complete description of the sampling and analysis method is described in Fuentes et al. (1996) for the 1993 field campaign; the methodology for 1995 was the same. The isoprene flux was then calculated through the gradient profile method:

$$
F=\frac{k u^{*}\left(C_{1}-C_{2}\right)}{\ln \left|\frac{z_{2}-d}{z_{1}-d}\right|+\Psi_{1}-\Psi_{2}},
$$

where concentrations $C_{1}$ and $C_{2}$ are measured at heights $z_{1}$ and $z_{2}\left(>z_{1}\right)$, respectively, and $\Psi_{\mathrm{i}}$ are the BusingerDyer stability corrections. Profiles of meteorological variables such as air temperature, dewpoint, relative humidity, solar radiation, and wind velocity components and direction as well as mixing ratios of $\mathrm{CO}_{2}$ and $\mathrm{H}_{2} \mathrm{O}$ vapor were measured continuously throughout the sampling season. For a more detailed description of measured variables, tower setup, and instrumentation, see Lo (1995) and Fuentes et al. (1996). From the measurements of $u$, $u^{*}$, and heat flux density (3D sonic anemometer, model DAT-310, Kaijo Denki Ltd., Tokyo, Japan) at $33 \mathrm{~m}$, the roughness length and displacement height for the 1995 sampling season were calculated as $z_{0}=1.98 \mathrm{~m}$ and $d$ $=13.40 \mathrm{~m}$, using the procedure described by Fuentes et al. (1996) to estimate these parameters from measurements made within the transition layer.

The transition layer can be divided into two layers: the upper inertial sublayer (Tennekes 1973) in which fluxgradient relationships are valid, and the lower roughness sublayer immediately above the canopy where the validity is uncertain due to the proximity of the roughness elements (Raupach et al. 1980). Within the roughness sublayer, studies (reported by Cellier and Brunet 1992) have shown that the scalar eddy diffusivities are enhanced by factors of 2-3 over those predicted by similarity theory. Raupach (1994) estimated the upper limit of the roughness sublayer $Z_{w}$ by the relationship $\left(Z_{w}-d\right) /\left(h_{c}\right.$ $-d) \approx 2$, where $h_{c}$ is the mean canopy height. This would result in $Z_{w} \approx 31 \mathrm{~m}$ for the site during 1995 . Alternatively, Cellier and Brunet (1992) suggested that $Z_{w}-d \approx 3$ to $4 \delta$, where $\delta$ is the lateral separation scale of the main roughness elements. Fuentes et al. (1996) estimated $\delta \approx 2.6-3.2 \mathrm{~m}$ for the site, giving a range of 21-26 $\mathrm{m}$ for $Z_{w}$. This puts the lower observation height of $30 \mathrm{~m}$ within the upper limit of the roughness sublayer, while observations made at $42 \mathrm{~m}$ were in the inertial sublayer. This would be expected to result in the gradient approach underestimating the isoprene flux by only a small degree (Fuentes et al. 1996).

\section{Results and discussion}

For the dataset collected in 1986 at the site, the measured wind profile asymptotically approached the theoretical logarithmic profile with height, and the two became coincident above $40 \mathrm{~m}$. Also for realistic values of $d$ and $z_{0}$, calculated $u^{*}$ approached measured $u^{*}$ (Lo 1995). Our initial test data originally comprised five sampling days and were collected during the period of maximum foliage cover. These were examined according to the observations made by Lo (1995) in order to select profile data that were compatible with theoretical profiles. Only datasets where the measured $u$ profile at $45 \mathrm{~m}$ was within $\pm 20 \%$ of predicted values were used for subsequent analysis. The $20 \%$ limit was chosen in consideration of differences in canopy height between 1986 and 1995, and general uncertainties in measurements/models. In general, $|z / L|>0.9(|L|<50 \mathrm{~m})$ resulted in poor predictions of $u$ and such conditions, where the use of the above model (based on similarity theory) would be discouraged, were eliminated from further analysis. Overall, $47 \%$ of the hourly averaged measurements for the five test cases were retained. Among these, two days (12 July and 30 August) were chosen for our case studies since they represent extremes of stability in wind direction (steady vs variable), as seen in Fig. 1.

\section{a. Case study: 30 August 1995}

Mean wind directions on 30 August 1995 were fairly steady from the $\mathrm{SSE}\left(\approx 156^{\circ}\right)$ from 0300 to 2400 local time (Fig. 1a), and wind speeds ranged from 3.0 to 4.5 $\mathrm{m} \mathrm{s}^{-1}$. From 1000 to $2400 \mathrm{LT}$, the adjusted surface layer model was applicable under the requirements described above. Standard deviation of the wind direction $\sigma_{\theta}$ was 

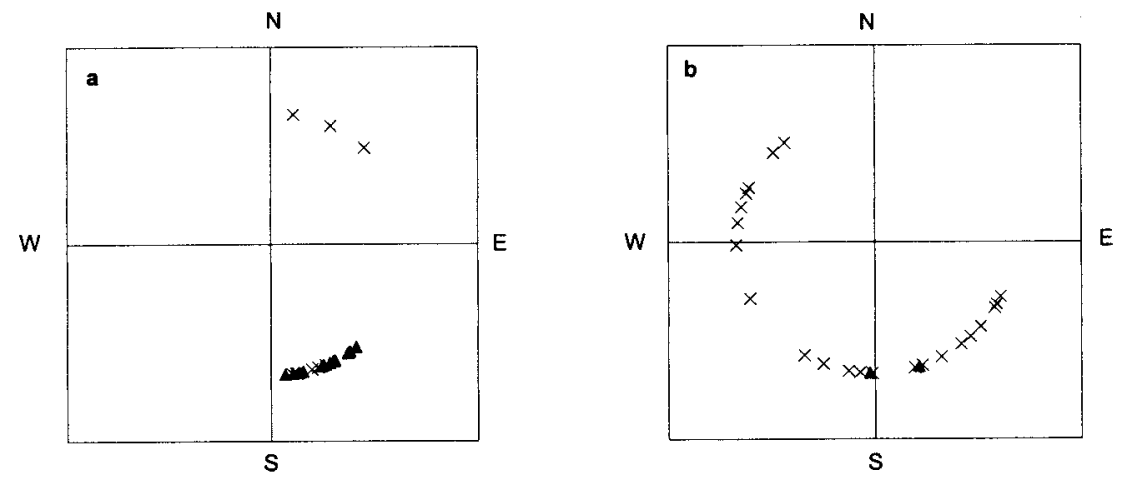

FIG. 1. Hourly averaged prevailing wind directions for (a) 30 Aug 1995 and (b) 12 Jul 1995 at the Camp Borden flux tower. The $\boldsymbol{\Delta}$ indicates dataset used in the analysis.

steady at $\approx 13^{\circ}$. During this period, two discrete stability conditions prevailed: 1000-1800 LT, $L$ changed from -315 to $-73 \mathrm{~m}$ around solar noon and decreased to $-780 \mathrm{~m}$ (mean $-240 \pm-73 \mathrm{~m}$ ), and from 1900 to $2400 \mathrm{LT}, L$ remained steady between 230 and $500 \mathrm{~m}$ (mean $340 \pm 41 \mathrm{~m}$ ). During these two prevailing stabilities, $u^{*}$ remained fairly steady with means of 0.61 $\pm 0.02 \mathrm{~m} \mathrm{~s}^{-1}$ and $0.52 \pm 0.02 \mathrm{~m} \mathrm{~s}^{-1}$, respectively, reflecting a certain degree of stationarity in the momentum field. The NNE winds did not meet the requirements of our screening process.

Using the scheme outlined by Schmid (1994), Eqs. (1) and (2) were used to calculate the upwind area (at mean aspen foliage density height of $17.5 \mathrm{~m}$ ) that would contribute to $80 \%$ of the measured isoprene concentration at 30 and $42 \mathrm{~m}$ for the two stability conditions.
Figure 2 illustrates the effect of instrument height and stability on the concentration FP. For unstable conditions $(L=-240 \mathrm{~m})$, the FP for a height of $30 \mathrm{~m}$ covers roughly half the upwind distance of the FP resolved at $42 \mathrm{~m}$ (extending up to $750 \mathrm{~m}$ ), whereas under stable conditions $(L=340 \mathrm{~m})$ the FP at $30 \mathrm{~m}$ covers less than one fourth the upwind distance of the FP at the higher elevation (extending up to $8.5 \mathrm{~km}$ ). Unstable conditions severely constrain the FP at all heights. With increasing instability the surface and atmosphere become more directly coupled so that the measured signal is linked more directly to sources closer to the instrument. Atmospheric stratification is the dominant factor in determining the size of the FP associated for a given height. The extended FP under stable nighttime conditions may have significant implications when interpreting flux calculat-
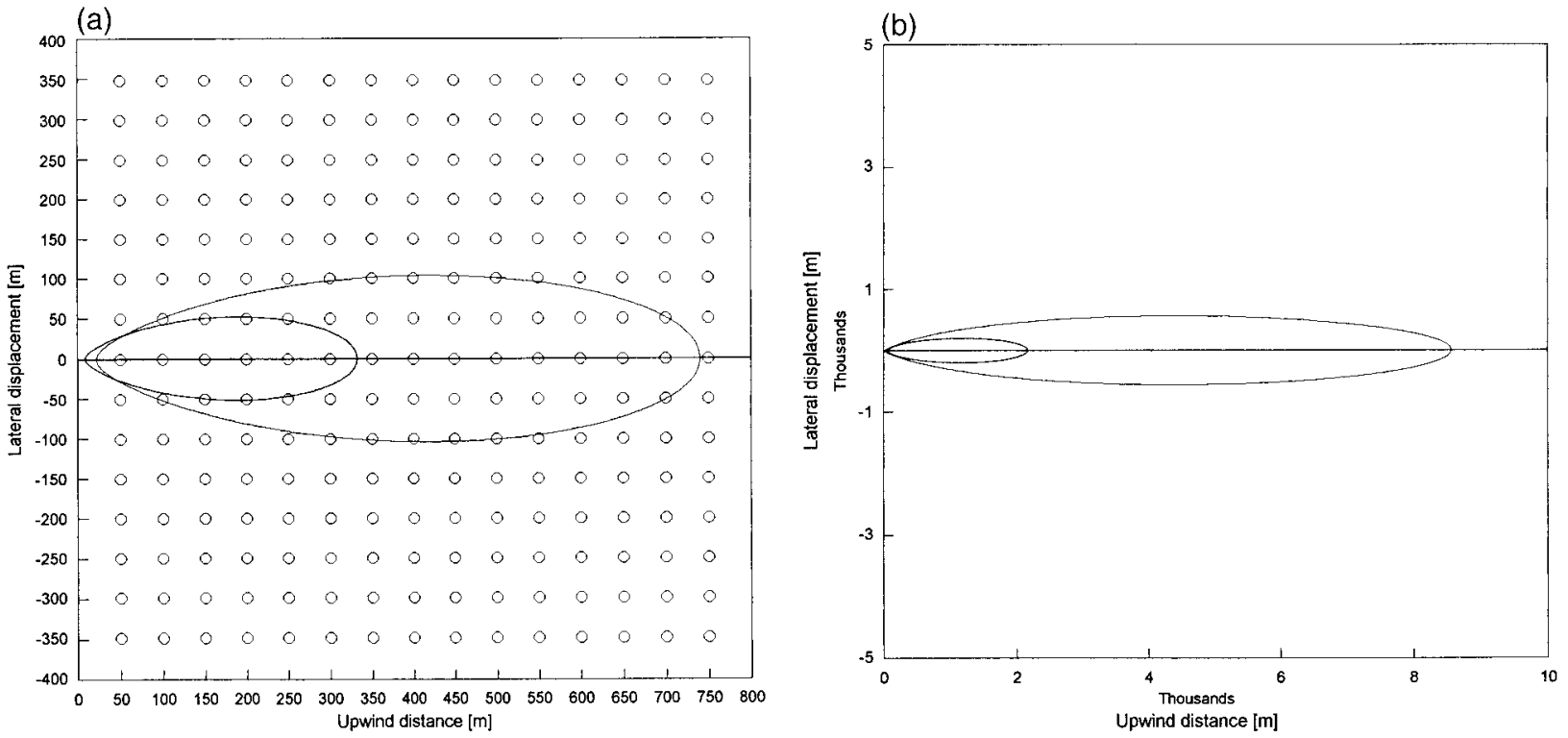

FIG. 2. (a) Concentration FPs ( $80 \%$ isopleth) under unstable daytime conditions $(L=-240 \mathrm{~m})$ of 30 Aug 1995 at Camp Borden. The larger FP is for the $42-\mathrm{m}$ measurement height, while the smaller is for the $30-\mathrm{m}$ measurement height. The circular grid markers at every 50 $\mathrm{m}$ simulate the distribution and diameter of isoprene emitting aspen clumps at the site. (b) Concentration FPs (80\% isopleth) under stable nighttime conditions $(L=340 \mathrm{~m}$ ) of 30 Aug 1995 at Camp Borden. The larger FP is for the 42-m measurement height, while the smaller is for the $30-\mathrm{m}$ measurement height. 


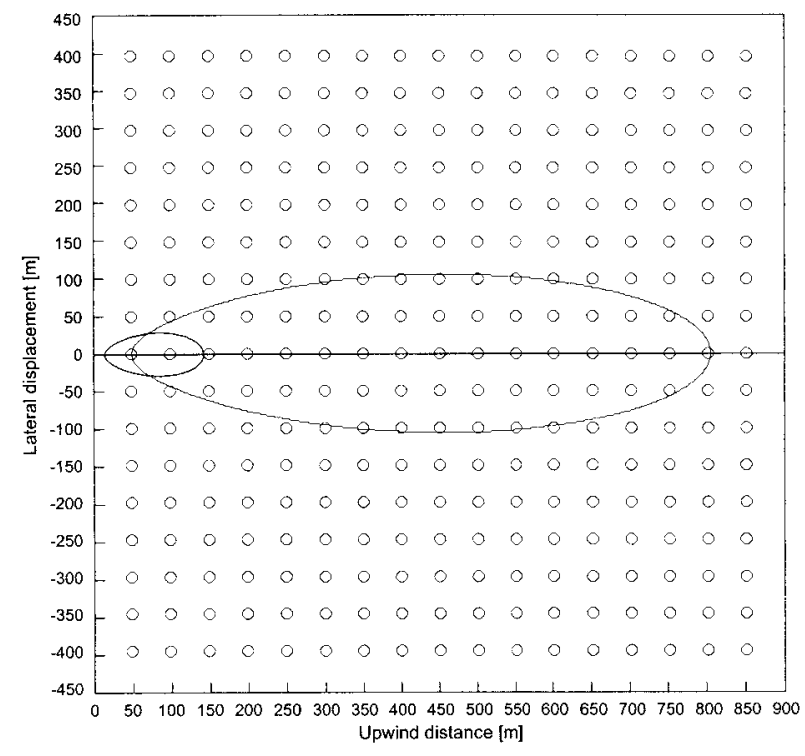

FIG. 3. Flux FPs ( $80 \%$ isopleth) at the 35.5-m height under unstable $(L=-240 \mathrm{~m})$ and stable $(L=340 \mathrm{~m})$ conditions of $30 \mathrm{Aug} 1995$ at Camp Borden. The spatially constrained FP occurred during the unstable condition. The circular grid markers at every $50 \mathrm{~m}$ simulate the distribution and diameter of isoprene emitting aspen clumps at the site.

ed from the concentration gradient. From 2200 to 2400 LT, the mean calculated flux was downward $(-0.042$ $\mu \mathrm{g} \mathrm{m}^{-2} \mathrm{~s}^{-1}$ ), suggesting isoprene deposition to the forest. The possibility that this observation was affected by anthropogenic isoprene emissions (e.g., car exhaust) from the town, located about $3 \mathrm{~km}$ south of the site (beyond the extent of the FP for $30 \mathrm{~m}$ but within that at $42 \mathrm{~m})$, cannot be excluded.

The flux was calculated from concentration gradients [Eq. (4)] at the mean geometric height of $35.5 \mathrm{~m}$. Using Eq. (3) in the flux form of Eq. (1), the FP contributing to $80 \%$ of the flux at $35.5 \mathrm{~m}$ was then calculated (Fig. $3)$. The effect of atmospheric stability is obvious. The areal coverage under $L=-240 \mathrm{~m}$ is only approximately $3 \%$ of the FP under $L=340 \mathrm{~m}$. If the forest is homogeneous or the source distribution is uniform at all scales, the spatial extent of the FP is of no consequence, but if the source distribution is nonuniform (clumped), extent and/or orientation of the FP may be crucial to the interpretation of measurements.

Assuming that the isoprene-emitting clumps of aspen are uniformly distributed at the nodes of a $50 \mathrm{~m} \times 50$ $\mathrm{m}$ grid (which would closely correspond to the clump distribution described above with hypotenuse $\approx 71 \mathrm{~m}$ ), as shown in Figs. 2a and 3, one can readily see the FP encompassing very different numbers of clumps depending upon wind direction and/or source distribution pattern, especially for the constrained FPs under instability. In order to examine the effects of source distribution within an FP, clump source strength (assuming uniform strength) was back-calculated from measured concentration [Eqs. (1) and (2)] and then used to esti-
TABLE 2. Back-calculated clump source strength of isoprene $Q$ using measured concentrations $C(30 \mathrm{~m})=2.41 \mu \mathrm{g} \mathrm{m}^{-3}$ and $C(42 \mathrm{~m})$ $=1.97 \mu \mathrm{g} \mathrm{m}^{-3}$ for case study day 30 Aug $1995 ; L=-240 \mathrm{~m}$.

\begin{tabular}{|c|c|c|c|}
\hline $\begin{array}{c}z \\
(\mathrm{~m})\end{array}$ & $\begin{array}{l}\text { Orientation of FP } \\
\text { with respect } \\
\text { to source } \\
\text { distribution }\left(^{\circ}\right)\end{array}$ & $\begin{array}{c}\text { No. of source } \\
\text { clumps within } \\
\text { FP }\end{array}$ & $\begin{array}{c}Q \\
\text { (mg s} \mathrm{s}^{-1} \text { per } \\
\text { clump) }\end{array}$ \\
\hline 30 & $0 / 90$ & 15 & 1.3 \\
\hline 30 & $\sim 45$ & 13 & 2.5 \\
\hline 42 & $0 / 90$ & 51 & 1.6 \\
\hline 42 & $\sim 45$ & 53 & 1.7 \\
\hline \multicolumn{4}{|c|}{ Mean $Q 1.8$} \\
\hline
\end{tabular}

mate the flux [Eqs. (1) and (3)]. This estimated flux was then compared with the flux calculated from Eq. (4) (henceforth referred to as the measured flux). We used daytime conditions for our analysis since nighttime emissions were assumed to be negligible.

Depending upon the orientation of the source distribution, between 13 and 15 clumps were within the 30-m height FP (Table 2). This corresponded to a back-calculated isoprene source strength $Q$ of between 2.5 and $1.3 \mathrm{mg} \mathrm{s}^{-1}$ per clump for the mean measured concentration of $2.41 \pm 0.15 \mu \mathrm{g} \mathrm{m}^{-3}$. This is a significant orientation-dependent difference between the two estimates even though the number of clumps differed by only 2 . At the 42-m height, the FP covered between 51 and 53 clumps and gave a $Q$ of $1.6-1.7 \mathrm{mg} \mathrm{s}^{-1}$ per clump for the mean measured concentration of $1.86 \pm 0.11 \mu \mathrm{g} \mathrm{m}^{-3}$. This difference is not significant and suggests that at this higher elevation the source distribution tends to be "seen" as uniform within the FP, with resolution of the distribution being lost. Assuming a mean $Q$ of $1.8 \mathrm{mg}$ $\mathrm{s}^{-1}$ per clump, flux estimates were then calculated for different source distributions/orientations. The calculated fluxes ranged from 0.15 to $0.60 \mu \mathrm{g} \mathrm{m}^{-2} \mathrm{~s}^{-1}$ depending upon the number of clumps seen by the FP (Table 3); this corresponded to $38 \%$ to $150 \%$ of the mean measured flux $\left(0.40 \pm 0.04 \mu \mathrm{g} \mathrm{m}^{-2} \mathrm{~s}^{-1}\right)$. For a source distribution that assumed four clumps to be evenly distributed within the FP, the calculated flux approximately equaled the measured one. The above analysis corrected for the fact that the FP was for the 80th percentile isopleth.

\section{b. Case study: 12 July 1995}

Wind direction on 12 July 1995 backed steadily from the NW to the ESE throughout the day with half-hourly

TABLE 3. Estimated isoprene flux from source clumps within flux FP for case study day 30 Aug 1995. Mean measured flux $=0.40 \pm$ $0.04 \mu \mathrm{g} \mathrm{m}^{-2} \mathrm{~s}^{-1} ; L=-240 \mathrm{~m}$.

\begin{tabular}{ccc}
\hline $\begin{array}{c}\text { Calculated } \\
\text { flux } \\
\left(\mu \mathrm{g} \mathrm{m}^{-2} \mathrm{~s}^{-1}\right)\end{array}$ & $\begin{array}{c}\text { Percent of } \\
\text { mean } \\
\text { measured flux }\end{array}$ & $\begin{array}{c}\text { Source distribution } \\
\text { within FP }\end{array}$ \\
\hline 0.60 & 150 & 3 clumps all in centerline \\
0.44 & 109 & 4 clumps evenly distributed \\
0.31 & 76 & 2 clumps all in centerline \\
0.15 & 38 & 4 clumps toward the edges \\
\hline
\end{tabular}


TABLE 4. Effect of variable wind direction, i.e., large $\sigma_{\theta}$ on flux estimation. Mean measured flux for 12 Jul $1995(1000-1700$ LT) $=$ $1.44 \pm 0.27 \mu \mathrm{g} \mathrm{m}^{-2} \mathrm{~s}^{-1}$; range $0.71-2.97 \mu \mathrm{g} \mathrm{m}^{-2} \mathrm{~s}^{-1}$.

\begin{tabular}{cl}
\hline $\begin{array}{c}\text { Calculated flux } \\
\left(\mu \mathrm{g} \mathrm{m}^{-2} \mathrm{~s}^{-1}\right)\end{array}$ & Source distribution within FP \\
\hline 1.61 & 8 clumps with 4 along centerline \\
0.57 & 6 clumps all well within \\
0.28 & 7 clumps with 3 along centerline \\
0.27 & 6 clumps evenly distributed \\
0.20 & 6 clumps with 2 along the edge \\
\hline
\end{tabular}

averaged standard deviation of the wind direction ranging from $7^{\circ}$ to $25^{\circ}$ between 0900 and 1800 LT. During this period, winds were light $\left(0.6-1.9 \mathrm{~m} \mathrm{~s}^{-1}\right)$. Isoprene concentrations ranged from 3.28 to $7.92 \mu \mathrm{g} \mathrm{m} \mathrm{m}^{-3}$ (mean $4.71 \pm 0.54 \mu \mathrm{g} \mathrm{m}^{-3}$ ) and 0.37 to $5.94 \mu \mathrm{g} \mathrm{m}^{-3}$ (mean $3.03 \pm 0.61 \mu \mathrm{g} \mathrm{m}^{-3}$ ) at $30 \mathrm{~m}$ and $42 \mathrm{~m}$, respectively. The Obukhov length ranged from -1 to $+120 \mathrm{~m}$. Similarity conditions were only satisfied for a 2 -h period, 1100-1300 LT, during which calculated wind speed at $45 \mathrm{~m}$ was within $20 \%$ of the measured speed, $u^{*}$ was $\approx 0.3 \mathrm{~m} \mathrm{~s}^{-1}, L \approx-28 \mathrm{~m}$, and $\sigma_{\theta} \approx 17^{\circ}$. Mean isoprene concentrations were $3.47 \mu \mathrm{g} \mathrm{m}^{-3}$ and $2.63 \mu \mathrm{g} \mathrm{m}^{-3}$ at $30 \mathrm{~m}$ and $42 \mathrm{~m}$, respectively, during this interval and the mean measured flux was $0.72 \mu \mathrm{g} \mathrm{m}^{-2} \mathrm{~s}^{-1}$.

The shifting wind direction and high variability of $\sigma_{\theta}$ would result in a more time-varying, broader FP, covering a wider range in the number of clump sources. The changes in FP size/shape have the potential to affect the observed flux for a nonuniform source distribution such as that found at the local tower scale. We first isolated this effect on flux measurements by calculating the flux FP for $\sigma_{\theta}$ $=25^{\circ}$, using the same meteorological parameters and source strength as on 30 August 1995, for the different combinations of sources that could "fit" within the FP. The results are listed in Table 4. Calculated flux ranged from 0.20 to $1.61 \mu \mathrm{g} \mathrm{m}^{-2} \mathrm{~s}^{-1}$, compared to the measured flux, which ranged from 0.71 to $2.97 \mu \mathrm{g} \mathrm{m}^{-2} \mathrm{~s}^{-1}$.

The 2-h period where simulation criteria were satisfied fell within the 1000-1700 LT period of strong atmospheric instability. To examine the effects of the much more constrained FP (compared to 30 August), the concentration and flux FPs were then recalculated for the meteorological conditions prevailing during that 2-h period. For $L=-28 \mathrm{~m}$, the concentration FP $(P$ $=0.8$ ) had a maximum upwind extent of $175 \mathrm{~m}$ and a width of $70 \mathrm{~m}$ for the $42-\mathrm{m}$ height, and an upwind extent of only $87 \mathrm{~m}$ and width of $37 \mathrm{~m}$ for the $30-\mathrm{m}$ measurement height. This means that, especially for the lower height, the FP might completely miss source clumps. Back-calculating $Q$ using the concentration measured at $30 \mathrm{~m}$ resulted in $Q$ ranging from 1.7 to $21.9 \mathrm{mg} \mathrm{s}^{-1}$ per clump, depending upon clump distribution. However, due to the larger size of the FP at $42 \mathrm{~m}, Q$ only ranged from 3.8 to $6.7 \mathrm{mg} \mathrm{s}^{-1}$ per clump. Therefore, a mean $Q(42 \mathrm{~m})=5.2 \pm 0.6 \mathrm{mg} \mathrm{s}^{-1}$ per clump was used for estimating the flux. Clearly, this extrapolated source
TABLE 5. Estimated flux between 1100-1300 LT on 12 Jul 1995; $L=-28 \mathrm{~m}, Q=0.27 \mathrm{mg} \mathrm{s}^{-1}\left(4 \mathrm{~m}^{2}\right)^{-1}$; measured flux $=0.72 \mu \mathrm{g}$ $\mathrm{m}^{-2} \mathrm{~s}^{-1}$.

\begin{tabular}{cl}
\hline \hline $\begin{array}{c}\text { Estimated flux } \\
\left(\mu \mathrm{g} \mathrm{m}^{-2} \mathrm{~s}^{-1}\right)\end{array}$ & \multicolumn{1}{c}{ Source distribution } \\
\hline 136.4 & Entire source filling FP \\
11.3 & Source filling farther half of FP \\
2.6 & Source 20 m upwind of FP \\
0.5 & Source 50 m upwind of FP \\
\hline
\end{tabular}

strength is higher than that estimated for the 30 August case. To what degree this difference is real, potentially associated with leaf temperature differences between the two days, would be a subject for further analysis.

The size of the flux FP was severely constrained by the strong instability, with upwind extent ranging from only 4 to $16 \mathrm{~m}$ and a width of $8 \mathrm{~m}$. (The effect of the prevailing light winds had negligible influence on the FP size. When wind conditions for 30 August were used instead, the upwind extent of the FP increased by only $2 \mathrm{~m}$ with no change in lateral dimensions.) The limited spatial coverage of the FP was equivalent to the area covered by a single clump source. This required a higher degree of resolution in the analysis, in which the clump source was partitioned into $4 \mathrm{~m}^{2}$ subareas, rather than being considered as a point source. Scenarios that considered the FP completely covering, partially covering, and completely missing a source clump were used to estimate the flux measured at $35.5 \mathrm{~m}$ (Table 5). Estimates ranged from 0.51 to $136.38 \mu \mathrm{g} \mathrm{m}^{-2} \mathrm{~s}^{-1}$, while the measured isoprene flux was $0.72 \mu \mathrm{g} \mathrm{m}^{-2} \mathrm{~s}^{-1}$. This suggests that the measured flux generally reflected source clumps located beyond the $80 \%$ isopleth of the flux footprint. Constrained FPs may potentially cause a large flux variability for nonuniformly distributed sources.

\section{Conclusions}

Considerations of FP size and source distribution within the FP and with respect to the observation point are necessary in order to interpret both concentration and flux measurements above the forest. This is particularly true for a nonuniform source distribution where the relative strengths of individual sources should also be known. Under daytime instability and steady wind direction, flux measurements varied by only $27 \%$ of the daytime mean, whereas under nonsteady wind direction, variability was doubled at an order of $53 \%$ of the daytime mean. This variability could be reproduced in estimates made for various combinations of wind direction and fluctuation in wind direction, FP size (measurement height and atmospheric stability), and source density/ distribution, under the prevailing meteorological conditions. These estimates demonstrate that the measured concentration or flux is extremely sensitive to the number of sources within a constrained FP. At $30 \mathrm{~m}$, the inclusion or exclusion of just two source clumps (from 
15 to 13) within the concentration FP resulted in the estimated source strength per aspen clump increasing from 1.3 to $2.5 \mathrm{mg}$ isoprene $\mathrm{s}^{-1}$ per clump. By contrast, the estimated source strength at the higher elevation of $42 \mathrm{~m}$, with a larger FP, was much less sensitive to small differences in the number of clumps $(1.6-1.7 \mathrm{mg}$ isoprene $\mathrm{s}^{-1}$ per clump). This sensitivity was also illustrated by the flux estimates where a difference of only one source clump from a total of two to three within the FP resulted in flux estimates that varied from $76 \%$ to $150 \%$ of the mean measured flux.

The problem of adequately sampling ("seeing") nonuniform sources at a given measurement height becomes more acute during extremely unstable conditions when the FP is so constrained and close to the measurement tower that it can either completely enclose a source or miss it entirely, resulting in estimates varying by several orders of magnitude (136.4 $\mu \mathrm{g} \mathrm{m}^{-2} \mathrm{~s}^{-1} \mathrm{vs} 0.5 \mu \mathrm{g} \mathrm{m}^{-2}$ $\mathrm{s}^{-1}$ ). Under stable nighttime conditions, the opposite problem is encountered, with an extended FP, which may well see beyond the limits of the experimental site and incorporate extraneous sources into the measured concentration or flux.

This raises the important question to what extent changes in measured values reflect variations in the coverage of sources by a varying FP rather than variations in actual biogenic emissions in response to environmental forcing. At higher observation levels and/or increased stability, source distribution or density tends to be seen as more homogeneous and becomes less of an influencing factor on the measured quantities. However, for very extended FPs, we must consider the source distribution on a larger regional scale, which might include emissions from anthropogenic sources and different forest types/conditions. This might help to explain downward-directed flux sometimes observed during stable nighttime conditions. Finally, the inclusion of FP considerations could help to decrease the scatter currently observed between modeled and measured emissions over a heterogeneous forest by specifying the area of the forest effectively sampled under given wind and stability conditions. This is essential to the improvement of physiological/microclimatological emission models, so that they can be used with more confidence as forcing modules within climate models.

Acknowledgments. The Atmospheric Environment Service (AES) of Environment Canada, which supported the field project, is gratefully acknowledged. The authors would like to thank Drs. H. H. Neumann and G. den Hartog, and Mr. R. Staebler for their field support. Expressions of thanks are also extended to Mr. J. Deary of AES, who provided talented technical assistance in operation and maintenance of instrumentation, and Dr. D. Wang, who contributed with isoprene concentration measurements.

\section{REFERENCES}

Businger, J. A., J. C. Wyngaard, I. Izumi, and E. F. Bradley, 1971: Flux profile relationships in the atmospheric surface layer. $J$. Atmos. Sci., 28, 181-189.

Cellier, P., and Y. Brunet, 1992: Flux-gradient relationships above tall plant canopies. Agric. For. Meteor., 58, 93-117.

Fehsenfeld, F., and Coauthors, 1992: Emissions of volatile organic compounds from vegetation and the implications for atmospheric chemistry. Global Biogeochem. Cycles, 6, 389-430.

Finn, D., B. Lamb, M. Y. Leclerc, and T. W. Horst, 1996: Experimental evaluation of analytical and Lagrangian surface-layer flux footprint models. Bound.-Layer Meteor., 80, 283-308.

Fuentes, J. D., D. Wang, H. H. Neumann, T. J. Gillespie, G. den Hartog, and T. F. Dann, 1996: Ambient biogenic hydrocarbons and isoprene emissions from a mixed deciduous forest. J. Atmos. Chem., 25, 67-95.

,$- \ldots$, and L. Gu, 1999: Seasonal variations in isoprene emissions from a deciduous boreal aspen forest. J. Applied Meteor., 38, 855-869.

Guenther, A., P. Zimmerman, and M. Wildermuth, 1994: Natural volatile organic compound emission rate estimates for U.S. woodland landscapes. Atmos. Environ., 28, 1197-1210.

— compound emissions. J. Geophys. Res., 100, 8873-8892.

Horst, T. W., and J. C. Weil, 1992: Footprint estimation for scalar flux measurements in the atmospheric surface layer. Bound.Layer Meteor., 59, 279-296.

— and — 1994: How far is far enough? The fetch requirements for micrometeorological measurements of surface fluxes. J. Atmos. Oceanic Technol., 11, 1018-1025; Corrigenda, 12, 447.

Kaharabata, S. K., P. H. Schuepp, S. Ogunjemiyo, S. Shen, M. Y. Leclerc, R. L. Desjardins, and J. I. MacPherson, 1997: Footprint considerations in BOREAS. J. Geophys. Res., 102, 29 113-29 124.

Kaimal, J. C., and J. J. Finnigan, 1994: Atmospheric Boundary Layer Flows. Oxford University Press, 289 pp.

Lamb, B., and Coauthors, 1996: Evaluation of forest canopy models for estimating isoprene emissions. J. Geophys. Res., 101, $22787-22797$.

Leclerc, M. Y., and G. W. Thurtell, 1990: Footprint predictions of scalar fluxes using a Markovian analysis. Bound.-Layer Meteor., 53, 247-258.

Lo, A. K.-F., 1995: Determination of zero-plane displacement and roughness length of a forest canopy using profiles of limited height. Bound.-Layer Meteor., 75, 381-402.

Pasquill, F., and F. B. Smith, 1983: Atmospheric Diffusion. 3d ed. John Wiley and Sons, $437 \mathrm{pp}$.

Raupach, M. R., 1994: Simplified expressions for vegetation roughness length and zero-plane displacement as functions of canopy height and area index. Bound.-Layer Meteor., 71, 211-216.

- A. S. Thom, and I. Edwards, 1980: A wind-tunnel study of turbulent flow close to regularly arrayed rough surfaces. Bound.Layer Meteor., 18, 373-397.

_ J. J. Finnigan, and Y. Brunet, 1996: Coherent eddies and turbulence in vegetation canopies: The mixing layer analogy. Bound.-Layer Meteor., 78, 351-382.

Schmid, H. P., 1994: Source areas for scalars and scalar fluxes. Bound.-Layer Meteor., 67, 293-318.

Schuepp, P. H., M. Y. Leclerc, J. I. MacPherson, and R. L. Desjardins, 1990: Footprint prediction of scalar fluxes from analytical solutions of the diffusion equation. Bound.-Layer Meteor., 50, $355-374$.

, J. I. MacPherson, and R. L. Desjardins, 1992: Adjustment of footprint correction for airborne flux mapping over the FIFE site. J. Geophys. Res., 97, 18 455-18 466.

Tennekes, H., 1973: Similarity laws and scale relations in planetary boundary layers. Workshop on Micrometeorology, D. A. Haugen, Ed., Amer. Meteor. Soc., 177-216.

Wilson, J. D., and G. E. Swaters, 1991: The source area influencing a measurement in the planetary boundary layer: The "footprint" and the "distribution of contact distance." Bound.-Layer Meteor., 55, 25-46. 